\title{
The effect of PVC's resin K-value on the mechanical properties of the artificial leather
}

\author{
Muh. Wahyu Sya'bani ${ }^{1 *}$, Cynthia Devi ${ }^{1}$, Indri Hermiyati ${ }^{1}$, Andreas D.Angkasa ${ }^{2}$ \\ ${ }^{1}$ Department of Rubber and Plastics Processing Technology, Polytechnic of ATK Yogyakarta, Jl. Ring Road Selatan, Glugo, \\ Panggungharjo, Sewon, Bantul, Yogyakarta 55188, Indonesia \\ ${ }^{2} \mathrm{PT}$. Sempurna Indah Multinusantara, Jl. Raya Dayeuh Kolot No. 179, Bandung 40258, Indonesia \\ * Corresponding author. Telephone +62 274383727 \\ E-mail: mw-syabani@kemenperin.go.id
}

Submitted: 7 October 2019

Revised: 8 December 2019

Accepted: 12 December 2019

\begin{abstract}
Artificial leather offer wide variety of application thus the demand is increased over time. The variation of the product needs different properties that can be achieved using resin with suitable k-value.This works reports the influence of the resin $\mathrm{k}$-value on the mechanical properties of the artificial leather. The combination of various resin with different k-value $(66,68,72,74$, and 76)is used and the tensile strength and elongation at break of the product were evaluated. The results show that blending the PVC resin with different k-value can be used to adjust the easier processing of the lower k-value and better mechanical properties of the higher k-value. Larger k-value differences between two resin make more difficulties of resin blending thus give more defect. For the blending of two resin, the tensile strength and elongation value would be between both of the resin initial properties. The final properties will be closer to the resin with a higher percentage in the resin blending.
\end{abstract}

Keywords: artificial leather, elongation, K-value, tensile.

\section{INTRODUCTION}

Nowadays, artificial leather has becomeimportant materials that widely used to substitute genuine leather in the automotive interior, clothing, footwear, sofa fabric, decoration, and other application (Pimapunsri et al., 2017). Comparing to genuine leather, these materials have stable production and lower production price, thus have obtained a good market (Gurera \& Bhushan, 2018). Artificial leather usually consists of top coat, middle coat, base coat, and backing cloth.

Spreading is most widely used in the manufacturing of artificial leather. This method consists of coating plastisol on a moving fabric using a roller or a knife (Pimapunsri et al., 2017; Rybachuk et al., 2007). The processing through plastisol is one of the most efficient procedures since its ease processing and low equipment costs (Rybachuk et al., 2007; Zadhoush et al., 2004). Plastisolis prepared by mixing the components (polyvinyl chloride resin, fillers, pigments, plasticizers, adhesives, and other additives) in certain sequences.

The processing using plastisolis close related to a fluid system. A fluid can be anything from substance of water-like consistency to high viscosity, plastic-like mass. There are many parameters that can influence the rheological behavior, such as processing conditions, temperature, plastisol contents, K-value and plastisol type (Zadhoush et al., 2004). Flow parameter and paste rheology are important parameters during coating processing and influences the properties of the final product (Du et al., 2012).

The rheological, mechanical and thermal properties of the polyvinyl chloride (PVC) are dependent on the $\mathrm{K}$-value and the various additives used in the formulation (Marceneiro et al., 2018; Sholeh \& Rochani, 2018). K-value or viscosity number is an indicator of their molecular weight and degree of polymerization for the PVC used (Marceneiro et al., 2018). In the making of artificial leather, emulsion PVC resin is used. When E-PVC resins are mixed with a liquid plasticizer, a paste 
(plastisol) is produced due to the surfactant layer around the grain surface preventing plasticizer adsorption at room temperature. Consequently, these resins are called paste resins which are used in a wide range of specialty applications such as coating, dipping or spreading. Resins are available commercially for differing molecular weight, porosity, viscosity, speed of gelation, clarity and gloss level. For example, K-values range between 64 to 80 are suitable for automotive interior materials corresponding to medium to high molecular weight (Marceneiro et al., 2018).

Fikentscher K-value is the molecular weight distribution of PVC that estimated from the dilute solution viscosity measurements (Coelho et al., 2006; Mehdipour et al., 2017). The K-value can be calculated from equation 1 .

$$
\ln \left(\frac{\eta}{\eta_{0}}\right)=\frac{c K}{1000}\left(\frac{75 K}{1.5 c K+1000}+1\right)
$$

Where $\eta, \eta_{0}$, and $\mathrm{c}$ are the solvent viscosity, PVC solution viscosity, and concentration, respectively.

Sometimes, resins with optimal K-value for specific processing needs are not available commercially. Therefore, the blending of PVC resins with different $\mathrm{K}$-values can be used to adjusting the melt rheology of a compound to processing machinery. Another advantages of the blending areto combine the better fusion properties of the lowerMolecular Weight (MW) component with the better mechanical properties of the higher MW materials (Pepperl, 2000).

There is some research that already discussed on artificial leather such as on surface modification (Sakmat et al., 2015), processing (Rohet al., 2014), thermal and mechanical properties modification (Ma et al., 2019; Maia et al., 2017; Pimapunsri et al., 2017; Yang et al., 2017). And some paper has also studied the effect of $\mathrm{k}$-value into the rheological behavior of plastisol (Zadhoush et al.,
Table 1. Plastisol Formulation.

\begin{tabular}{cc}
\hline Material & phr \\
\hline resin & 100 \\
DOP & 60 \\
CP & 20 \\
foam activator & 2.5 \\
foaming agents & 2.75 \\
calcium carbonate & 60 \\
pigment & $4 \%$ of the total formulation \\
\hline
\end{tabular}

2004) and molecular weight distribution (Pepperl, 2000). But there is limited discussion about the correlation between PVC's k-value with artificial leather properties. In this paper,the influence of $\mathrm{PVC}$ resin blending using different $\mathrm{k}$-value on the mechanical properties of the artificial leatherwere studied.

\section{MATERIALS AND METHOD Materials}

The materials used in this research are polyvinyl chloride emulsion (PVC-E) with k-value of $66,68,72,74$ and 76 ; plasticizer diisooctylphthalate (DOP), chlorinated paraffin (CP); filler (calcium carbonate), foam activator, foaming agent, pigment and backing cloth.

\section{Formulation}

The formulation used to make the singlecoating artificial leather is shown in table 1 . The variable used in this works is the PVC resin blending with different $\mathrm{k}$-value as shown in table 2 below.

\section{Procedure}

Skin plastisol was made using DOP, CP, foaming agent, and blowing agent that mixed for 1 minute at speed $30 \mathrm{rpm}$. Then, filler was added and mixed for 2 minutes at speed $30 \mathrm{rpm}$. Finally, resin was added using formulation in table 2 and mixed for 5 minutes at $30 \mathrm{rpm}$. The skin plastisol

Table 2. PVC Resin variables based on k-value.

\begin{tabular}{cccccccccc}
\hline Resin & k-value & \multicolumn{7}{c}{ Sample* } \\
\cline { 3 - 9 } & & D5A5 & D5B5 & D5C5 & D10 & D5E5 & D4B6 & D3B7 & D2B8 \\
\hline A & 66 & 50 & & & & & & & \\
B & 68 & & 50 & & & & 60 & 70 & 80 \\
C & 72 & & & 50 & & & & & \\
D & 74 & 50 & 50 & 50 & 100 & 50 & 40 & 30 & 20 \\
E & 76 & & & & & 50 & & & \\
\hline
\end{tabular}

* for example, D5A5 means the sample using a blend of resin D $50 \mathrm{phr}$ and A $50 \mathrm{phr}$ 
ready for coating.Adhesive plastisol was made using DOP, TXIB, DP 728 and filler that mixed for 1 minute at $30 \mathrm{rpm}$. Then, resin added and mixed for 5 minutes at $30 \mathrm{rpm}$.

The released paper is heated at $170-180^{\circ} \mathrm{C}$ for 20 seconds, then the skin plastisol was coated and heated at $190-200^{\circ} \mathrm{C}$ for 1 minute. The next step is coating using adhesive plastisol and laminating using backing cloth, then heated at $190-200^{\circ} \mathrm{C}$ for 1 minute. Finally cooling the coating at room temperature for 3 minutes.

The tensile strength and elongation test was using Universal Tensile Machine (UTM) Gester GT-K02. The specimen is prepared carefully by cutting the PVC sheet in rectangular shape, which measured $3 \mathrm{~cm}$ in width and $15 \mathrm{~cm}$ in length. Scanning Electron Microscope (SEM) miniSEM is used to study the surface morphology of the sample. Samples were sputtered using gold coating before SEM studies.

\section{RESULTS AND DISCUSSION}

The flow character of plastisols may depend on the composition, preparation conditions and shear rate in the course of their processing (Rybachuk et al., 2007). One of the important factorsin artificial leather processing is the plastisol viscosity, thus blending two resin with different $\mathrm{k}$-value will affect the process.In polyvinyl chloride processing, some micro defect would exist such as inclusions, microcrack, microporous, etc (Luo et al., 2012; Yang et al., 2008). Based on the organoleptic test using lamp behind the artificial leather sheet, there aremicroporous defect that occurs in some of the sample. This defect is also confirmed using SEM analysis as shown in figure 1 .

The microporous defect may occur because of the rheological behavior of the paste. The nature of the polymer can have a great influence on the rheological behavior that plays an important role in the coating processes. Higher k-value means higher viscosity, higher molecular weight but also better thermal stability (Coelho et al., 2006). In many instances, its necessary to increased or decreased the viscosity of the coating paste (Zadhoush et al., 2004). And this can be done by selecting the correct choice of PVC k-value. Unfortunately, not all the optimum $\mathrm{k}$-value for processing are

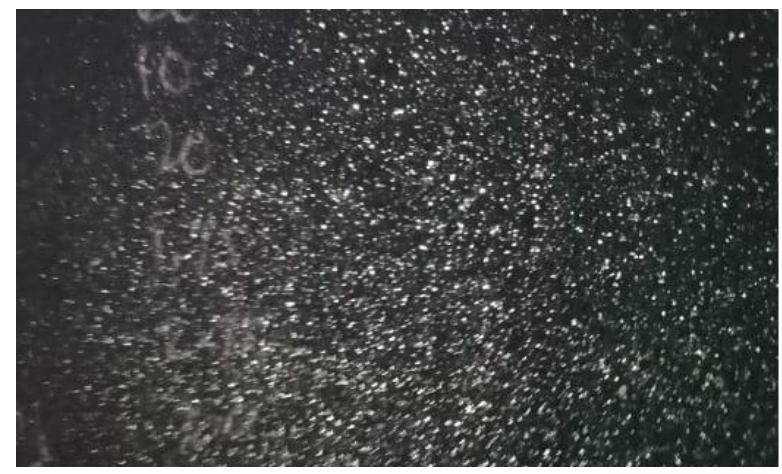

(b)

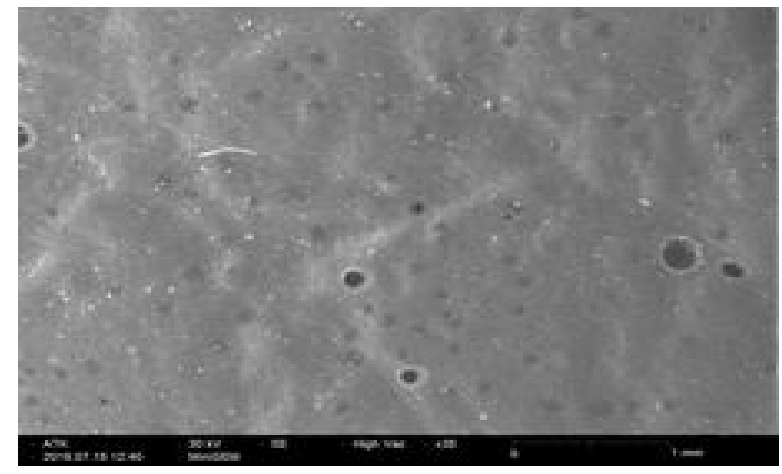

(d)

Figure 1. Surface morphology of the sample (a) without lamp test (b) with lamp testand ScanningElectron Micrographs 30x of the sample with (a) few (none of big dots) and (d) many microporous defects (more than 4 big dots). 
Table 3. Mechanical test result for the effect of resins k-value blending.

\begin{tabular}{cccccc}
\hline \multirow{2}{*}{ Sample } & Microporous & \multicolumn{2}{c}{ Tensile Strength, $\mathrm{N} / \mathrm{mm}^{2}$} & \multicolumn{2}{c}{ Elongation, \% } \\
\cline { 3 - 6 } & defect & Vertical & Horizontal & Vertical & Horizontal \\
\hline D5A5 & none & 3.95 & 1.28 & 43.61 & 181.98 \\
D5B5 & many & 3.28 & 1.81 & 41.97 & 178.44 \\
D5C5 & few & 3.69 & 1.51 & 44.21 & 197.70 \\
D10 & many & 4.88 & 1.35 & 48.36 & 173.61 \\
D5E5 & few & 3.92 & 1.60 & 43.65 & 184.33 \\
\hline
\end{tabular}

available commercially, thus blending two resin may solve the problems.

\section{Effect of Resins K-value on the Mechanical Properties of the Artificial Leather}

To studying the mechanical properties of the products, two resin with different $\mathrm{k}$-value are used to make the plastisol. Blending processes allows the combination of the useful and desired properties from different polymers ( $\mathrm{Du}$ et al., 2012). The mechanical properties of a blend depend on many factors including initial properties of blends material, composition, interfacial interaction and phase morphology (Mehdipour et al., 2017). In this paper, we focused on the variation ofblends constituent and composition.

\section{Effect of Resins K-value Blending}

According to Pepperl (2000), the blending of polymers with $\mathrm{k}$-values differing by less than 10 units will not affect the MW significantly. At the opposite, larger $\mathrm{k}$-value differences between the resin may result in difficulties at homogenizing the plastisol. Furthermore, incompatible polymer blends generally showed lower mechanical properties (Mehdipour et al., 2017). Therefore, in this works, the resin used in the blending process is

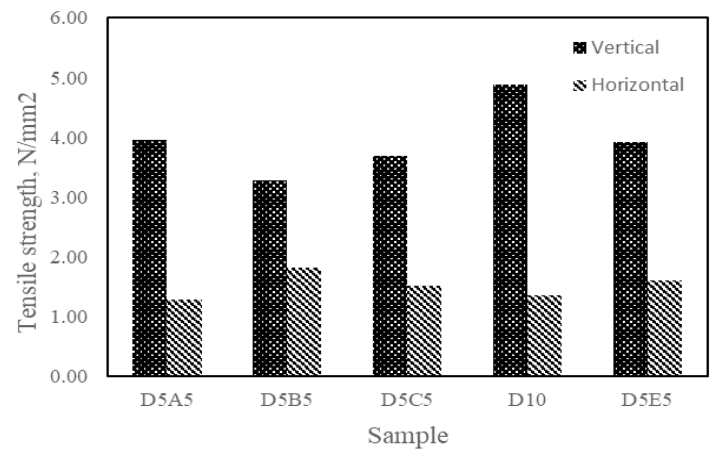

(a) from neighboring $\mathrm{k}$-value (the biggest differences is 10 units) in order to adjust the mean $\mathrm{k}$-value of the compound to processing equipments. The resulted mechanical test is shown in table 3 and figure 2 .

The blending of $50 \mathrm{phr}$ resin $\mathrm{A}$ and $50 \mathrm{phr}$ resin D (sample D5A5) gives none microporous defect since lower viscosity will help the easier spreading of plastisol when processed at the machinery. The defect is contributed to the rejectionof the final product, thus should be avoided. This can be the result of inhomogeneities from the bad-fusing resin particles of the high MW by the low shear forces present in the low MW resin(Pepperl, 2000). From figure 2(a) and 2 (b), the highest tensile strength $\left(4.88 \mathrm{~N} / \mathrm{mm}^{2}\right)$ and longest elongation (48.36\%) achieved by sample D10 (resin D $100 \mathrm{phr}$ ) for vertical test but gives many microporous defects. Pure resin $\mathrm{D}$, without blending with other resin give better mechanical properties since there are difficulties in interaction between non-similar long chains in blended polymer system (Mehdipour et al., 2017). Comparing to pure resin, the blending has slightly lower elongation $(2.26-5.07 \%)$, probably because of difficulties in obtained homogenous plastisol when blending two resin with different

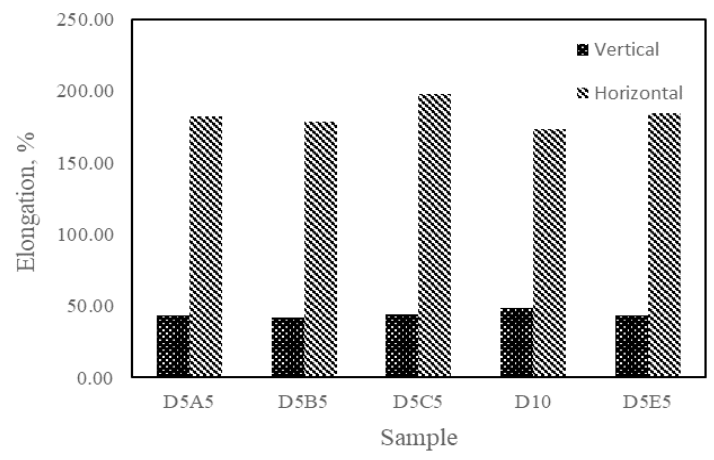

(b)

Figure 2. Effect of resins k-value blending (a) tensile strength (b) elongation. 
Table 4. Mechanical test result for the effect of resins k-value blending.

\begin{tabular}{cccccc}
\hline \multirow{2}{*}{ Sample } & Microporous & \multicolumn{2}{c}{ Tensile Strength, N/mm } & \multicolumn{2}{c}{ Elongation, \% } \\
\cline { 3 - 6 } & defect & Vertical & Horizontal & Vertical & Horizontal \\
\hline D10 & many & 4.88 & 1.35 & 48.36 & 173.61 \\
D5B5 & many & 3.28 & 1.81 & 41.97 & 178.44 \\
D4B6 & few & 2.66 & 1.48 & 42.82 & 170.6 \\
D3B7 & none & 2.62 & 1.63 & 39.17 & 170.38 \\
D2B8 & none & 2.93 & 1.48 & 43.61 & 166.04 \\
\hline
\end{tabular}

molecular weight. Some paper also shows similar negatives effect of blending inhomogeneitiesto the tensile strength and elongation (Mehdipour et al., 2017; Selvaraj et al., 2015). Therefore, there is should a compromise between the defect and mechanical properties that still suited the product requirements. The table 3 and figure 2 shows that the best compromise is sample D5A5 that gives none defect with tensile strength value 3.95/1.28 $\mathrm{N} / \mathrm{mm}^{2}$ (vertical/horizontal) and elongation 43.61/181.89\% (vertical/horizontal).

\section{Effect of Resin Percentage}

In this variation, two resin with different k-value (resin B and D) are blended together using a certain combination of phr. For studies of resin percentage effect, the resin D with k-value 74 is chosen because it has good tensile strength and elongation value for common artificial leather article. Whereas resin $\mathrm{B}$ has lower $\mathrm{k}$-value but the differences with resin $\mathrm{D}$ isin average number (6) comparing to the other resin. The result of the mechanical test are shown in table 4 and figure 3 .

As expected, for a combination of two resins, the mechanical properties of the combined resin will be between both of the resin. Since resin D have higher $\mathrm{k}$-value, thus higher phr of this resin will give product with higher tensile strength and elongation but have higher tendency to make defect.These phenomena can be explained that in generallonger polymerchains have less mobility (Mehdipour et al., 2017). On the opposite, a higher proportion of resin $\mathrm{B}$ with lower $\mathrm{k}$-value makes it easier to spreading and gives homogenous plastisol that have a lower probability to produce defect but also have lower mechanical properties. In this study, table 3 and 4 shows that the presence of micropores does not have a direct correlation with the mechanical properties, but influence the esthetics value of the product. Some work reported a similar conclusion (Mehdipour et al., 2017), but other papers reported that the internal defect (such as micropores) would make the product damaged, fracture and failure (Luo et al., 2012; Yang et al., 2008). As mentioned above, the combination of two resin with different $\mathrm{k}$-value is effective to choose the optimal product properties if the appropriate resin k-value is not available in the market.Each application produces a different shear to the coating paste at various machines; therefore, coating pastes need to have specific rheological properties to perform well (Du et al., 2012; Zadhoush et al., 2004).

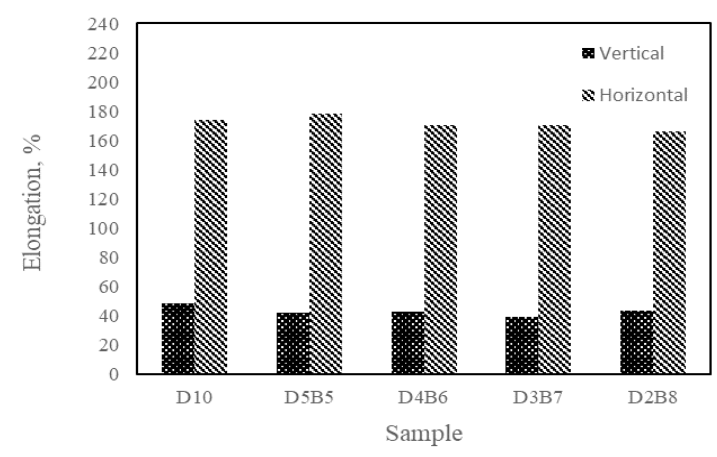

(b)

Figure 3. Effect of resins formulation (a) tensile strength (b) elongation. 


\section{CONCLUSION}

Blending PVC resin with different $\mathrm{k}$-value can be used to get the favorable properties of the product by balancing the easier processes of the lower $\mathrm{k}$-value resins and better mechanical properties of the higher $\mathrm{k}$-value.The properties of the product are dependent on the formulation, that the final properties will appear closer to the resin with a higher percentage.Sample D5A5 that consist of $50 \mathrm{phr}$ resin D (k-value 74) and $50 \mathrm{phr}$ resin A (k-value 66) considered good compromise between relatively good mechanical properties and esthetic value since it gives none microporous defect with tensile strength value of $3.95 \mathrm{~N} / \mathrm{mm} 2$ and elongation $43.61 \%$.

\section{ACKNOWLEDGEMENT}

The authors gratefully acknowledge the use of the services and facilities at PT. Sempurna Indah Multinusantara as the case study company.

\section{REFERENCES}

Coelho, J. F. J., Gonçalves, P. M. F. O., Miranda, D., \& Gil, M. H. (2006). Characterization of suspension poly(vinyl chloride) resins and narrow polystyrene standards by size exclusion chromatography with multiple detectors: Online right angle laser-light scattering and differential viscometric detectors. European Polymer Journal, 42(4), 751-763. https://doi.org/10.1016/j.eurpolymj.2005.09.023

Du, Y., Gao, J., Yang, J., \& Liu, X. (2012). Dynamic rheological behavior and mechanical properties and of PVC/ASA blends. Journal of Polymer Research, 19, 9993. https://doi.org/10.1007/ s10965-012-9993-3

Gurera, D., \&Bhushan, B. (2018). Fabrication of bioinspiredsuperliquiphobic synthetic leather with self-cleaning and low adhesion. Colloids and Surfaces A: Physicochemical and Engineering Aspects, 545, 130-137. https://doi.org/10.1016/j. colsurfa.2018.02.052

Luo, Y., Chen, S., Zhang, L., Su, J., Zhang, Y., \&Luo, S. (2012). Experimental studies on elastic cooling and pyromagnetic effect of polyvinyl chloride sheets with defects. Korea-Australia Rheology Journal, 24, 205-210. https://doi.org/10.1007/ s13367-012-0025-y

Ma, Y., Dang, X., \& Shan, Z. (2019). Thermal analysis and identification of potential fire-proof energy building material based on artificial leather. Journal of Thermal Science, 28, 88-96. https:// doi.org/10.1007/s11630-018-1054-8

Maia, I., Santos, J., Abreu, M. J., Miranda, T., Carneiro, N., \&Soares, G. M. B. (2017). PVC-based synthetic leather to provide more comfortable and sustainable vehicles. IOP Conference Series: Materials Science and Engineering, $254, \quad 122006 . \quad$ https://doi.org/10.1088/1757$\underline{899 X / 254 / 12 / 122006}$

Marceneiro, S., Alves, R., Lobo, I., Dias, I., de Pinho, E., Dias, A. M. A., Rasteiro, M. G.,\&de Sousa, H. C. (2018). Effects of poly(vinyl chloride) morphological properties on the rheology/aging of plastisols and on the thermal/leaching properties of films formulated using nonconventional plasticizers. Industrial \& Engineering Chemistry Research, 57(5), 1454-1467. https://doi. org/10.1021/acs.iecr.7b03097

Mehdipour, M. R., Talebi, S., \&Aghjeh, M. K. R. (2017). Effect of unplasticizedpoly vinyl chloride (UPVC) molecular weight and graftacrylonitrile-butadiene-styrene (g-ABS) content on compatibility and izodimpact strength of UPVC/g-ABS blends. Journal of Macromolecular Science, Part B, 56(9), 644-654. https://doi.org/1 $\underline{0.1080 / 00222348.2017 .1360684}$

Pepperl, G. (2000). Molecular weight distribution of PVC blends from resins with differentK values. Journal of Vinyl and Additive Technology, 6(4), 181-186. https://doi.org/10.1002/vnl.10250

Pimapunsri, K., Wuttipornpun, T., \&Veeranant, D. (2017). A study of the factors affecting the separation force of artificial leather laminating process. Key Engineering Materials, 728, 307312. https://doi.org/10.4028/www.scientific.net/ KEM.728.307

Roh, E. K., Oh, K. W., \& Kim, S. H. (2014). Effect of raising cycles on mechanical, comfort, and hand properties of artificial suede. Textile Research Journal, 84(18), 1995-2005. https://doi. org/10.1177/0040517514528561

Rybachuk, G. V., Kozlova, I. I., Mozzhukhin, V. B., \&Guzeev, V. V. (2007). PVC plastisols: Preparation, properties, and application. Polymer Science Series C, 49, 6-12.https://doi.org/10.1134/ $\underline{\mathrm{S} 181123820701002 \mathrm{X}}$

Sakmat, J., Lopattananon, N., \&Kaesaman, A. (2015). Effect of fiber surface modification on properties of artificial leather from leather fiber filled natural rubber composites. Key Engineering Materials, 659, 378-382. https://doi.org/10.4028/www. scientific.net/KEM.659.378

Selvaraj, D. E., Vijayaraj, R., Satheeshwaran, U., Nancy, J., Sugumaran, C. P., Kumar, M. R., Ganesan, J., Geethadevi, S., \& Kumar, S. D. (2015). Experimental investigation on electrical and mechanical characteristics of PVC cable insulation with silica nanofiller. Applied Mechanics and Materials, 749, 159-163. https://doi.org/10.4028/ www.scientific.net/AMM.749.159

Sholeh, M., \&Rochani, S. (2018). Pengaruh pemlastisdioktilftalat terhadap sifat fisis dan 
mekanis kulit sintetis. Jurnal Litbang Industri, 8(1), 17-22. https://doi.org/10.24960/jli. v8i1.3712.17-22

Yang, C., Wang, J., \& Li, L. (2017). A novel approach for developing high thermal conductive artificial leather by utilizing smart electronic materials. Textile Research Journal, 87(7), 816-828. https:// doi.org/10.1177/0040517516641356

Yang, Z., Luo, Y., Su, J., Zhang, Y., Deng, X., Chen, S., Deng, R., Ma, M., \&Zhang, L. (2008).
Thermomechanical coupling effect of PVC sheet with defects. Journal of Central South University of Technology, 15, 568-572. https:// doi.org/10.1007/s11771-008-0423-y

Zadhoush, A., Alsharif, M. A., \&Boukany, P. E. (2004). The Influence of K-value and plasticizer type on the rheological behaviour of plastisolused in coated fabrics. Iranian Polymer Journal, 13(5), 371-379. 
